\title{
Study on common phenotypic traits for purchasing sheep and their association with price and purpose of purchase in four markets of East Showa Zone
}

\author{
Getachew Terefe ${ }^{1}$, Teshale Teklue ${ }^{2}$, Ketema Shimelis ${ }^{1}$ \\ 1 Addis Ababa University, School of Veterinary Medicine, P. O. Box. 34, Debre-Zeit, Ethiopia \\ 2 Jimma University, College of Agriculture and Veterinary Medicine, P.O.Box.378, Jimma, \\ Ethiopia \\ Corresponding author: e-mail: getachew_terefe@yahoo.com
}

\begin{abstract}
A study was conducted in 2008 to assess the relationship between common phenotypic traits most considered for marketing sheep and the body weight and price of sheep at markets of four towns in East Showa zone. Six hundred randomly selected sheep purchased for various purposes were studied. The study methods include questionnaire surveys with 600 sheep buyers, color observations and five morphometric measurements on purchased animals. Questionnaire survey responses showed that sheep were commonly bought for slaughter. Almost all respondents consider in order of importance, chest size, lumbar width and tail width as criteria for selecting sheep of their choice. Brownish coat color followed by whitish predominates among the sheep purchased. The mean heart girth, chest size, lumbar width and tail width values of sheep bought for slaughter was significantly higher than for those bought for breeding and other purposes. Animals bought for slaughter and resale earned significantly higher price than those purchased for breeding and fattening. Linear measurement values except tail length and price had strong positive correlations $(\mathrm{P}<0.01)$. During sheep marketing, call price to selling price ratio shows that after an intense negotiation, sheep owners accepted $84 \pm 7.3 \%$ of the call price. In conclusion, sheep market customers' criteria to select sheep of their preference had strong association with the purpose of buying and the price paid after negotiation.
\end{abstract}

Keywords: Linear measurement, market, price, purpose of purchase, sheep

http://dx.doi.org/10.4314/evj.v16i2.2 


\section{Introduction}

Small ruminant production contributes significantly to the national and household economy in many countries. Ethiopia has 24,000,000 heads of sheep and 23,000,000 goats (CSA, 2004). The diversified topography and climatic conditions of Ethiopia had considerable contribution in the diversification of its livestock genetic resources (Beyne Kebede and Beruk Yemane, 1992; DAGRIS, 2006). An array of morphologial and phenotypic traits has been evaluated to classify different breeds of animals into various categories. Among these are mentioned skull morphology and size, body length, wither height, ear and tail length, lumbar width, coat color etc (Solomon Gizaw, 2009; Markos Tibbo et al., 2004; Vargas et al., 2007).

Studies made on indigenous sheep breeds revealed that between and within breed variation for growth is significant and indicated feasibility for productivity improvement through genetic means (Solomon Abegaz, 2002; Ewunetu Ermias et al., 2002; Markos Tibbo, 2006). In Ethiopia, sheep are purchased for various purposes at different occasions. Though the criteria used for selecting sheep from a diverse population at traditional markets may vary with the purpose for which the animal is purchased, weight determination is a major concern for almost all the sheep buyers, which often is judged only by visual observation and/or palpating various body parts of the animals.

However, information on the different types of criteria used for marketing sheep, and whether these market criteria have significant association with the buying price and purpose for which they are assessed is lacking. Such information provides firsthand idea for sheep breeders so as to improve production according to market demand. It also gives indications about the market (bargaining) price of sheep to the consumers. The objectives of this study were therefore to assess the phenotypic/morphological traits most considered by sheep consumers/breeders during marketing and the association of these with the price and purpose for which the animals were purchased.

\section{Material and methods}

\section{Study Area and study animals}

The study was conducted from October 2007 to May 2008 in four towns (Dukem, Bishoftu, Modjo and Adama) along $100 \mathrm{~km}$ distance east of the Capital, Addis Ababa. Data for this study were collected from open sheep-market places located in the centers of the aforementioned areas. A total of 600 sheep bought 
for various purposes were included. Accordingly, a systematic random sampling technique was employed on sheep buyers. Every other sheep buyer leaving the gate of the market place was considered for interview and his/her sheep for examination. If the individual was unwilling to participate on the interview, then the next person was taken. Only one sheep per buyer was examined and 15 respondents were interviewed per market day from each site.

\section{Study methodology}

A cross-sectional study design was followed, which includes semi-structured questioner survey (with sheep buyers), visual observations and linear measurements of selected body parts on purchased sheep.

\section{Questionnaire Survey}

A questionnaire survey, with semi-structured questionnaire format, was done with sheep buyers at the market places after they purchased animals of their choice by negotiating with the owners. It includes questions regarding the purpose for which they bought the animals, what criteria did they use to buy them, how much did the owners asked and how much did they paid after negotiation.

\section{Color observations}

After the animals were purchased, their color was registered as follows: whitish (white, cream, grayish-white), brownish (bay, brown, dark-brown), blackish (black) and spotted (consisting of two or more colors).

\section{Morphometry (linear measurements)}

Based on observation of frequent practices at sheep markets, chest size, lumbar width, tail length and tail width were identified for the morphometric linear measurements, using a measuring tape. Chest size was measured by holding the animal in upright position and keeping the front limbs straight close to the sternum. Measurement was done on the frontal plane from the right limb to left limb. Lumbar width was measured between the tips of the right and left transverse processes of the third to fourth lumbar vertebra. Tail width was measured at the broadest part while tail length was measured from the base of the tail to the tip. To estimate the body weight, heart girth was measured as the circumference around the body of the animal immediately behind the front legs as described by Markos Tibbo et al. (2004). 


\section{Data analysis}

Correlation coefficients between different parameters and comparisons of means of measured values using analysis of variance (ANOVA) were made using the SPSS statistical software. Proportions of male and females, color of animals purchased and purpose for which the animals were purchased were analyzed using X2 statistics. Means of linear measurements and prices of sheep were compared using one-way ANOVA.

\section{Result}

\section{Questioner survey responses}

By interviewing sheep buyers during market days at the local open markets, it was observed that sheep were bought for purposes such as slaughter, breeding, fattening and trading. As indicated in figure 1, significantly large proportion of sheep (75.3\%) was bought for slaughter (for home consumption and restaurants) compared to those for other uses $(\mathrm{P}<0.001)$. Majority of male sheep $(>95 \%)$ were purchased for slaughter while majority of females $(60 \%)$ were bought for breeding $(\mathrm{P}<0.001)$. The results of the questionnaire survey also showed that the most common criteria considered for selecting sheep of choice were chest size (89\%), lumbar width (99\%) and tail width (65\%). Color of sheep was important only for $25 \%$ of sheep users (Table 1). Indeed, it was noticed during the survey that almost all the sheep buyers palpate or grasp the chest, lumbar and tail areas in order to choose the best sheep of their interest within the limits of their paying capacity.

Table 1: Morphological criteria used by sheep buyers to select animals of their choice.

\begin{tabular}{lccc}
\hline Morphological criteria & & \% Responses & \\
\cline { 2 - 4 } & Yes & No & P-value \\
\hline Chest size & 89 & 11 & $\mathrm{P}<0.001$ \\
Lumbar width & 99 & 1 & $\mathrm{P}<0.001$ \\
Tail width & 65 & 35 & $\mathrm{P}<0.01$ \\
$\begin{array}{l}\text { Chest size +Lumbar } \\
\text { width }\end{array}$ & 88 & 12 & $\mathrm{P}<0.001$ \\
Chest size+ lumbar & & & $\mathrm{P}<0.01$ \\
width and Tail width & 59 & 41 & $\mathrm{P}<0.001$ \\
Color & 25 & 75 & \\
\hline
\end{tabular}




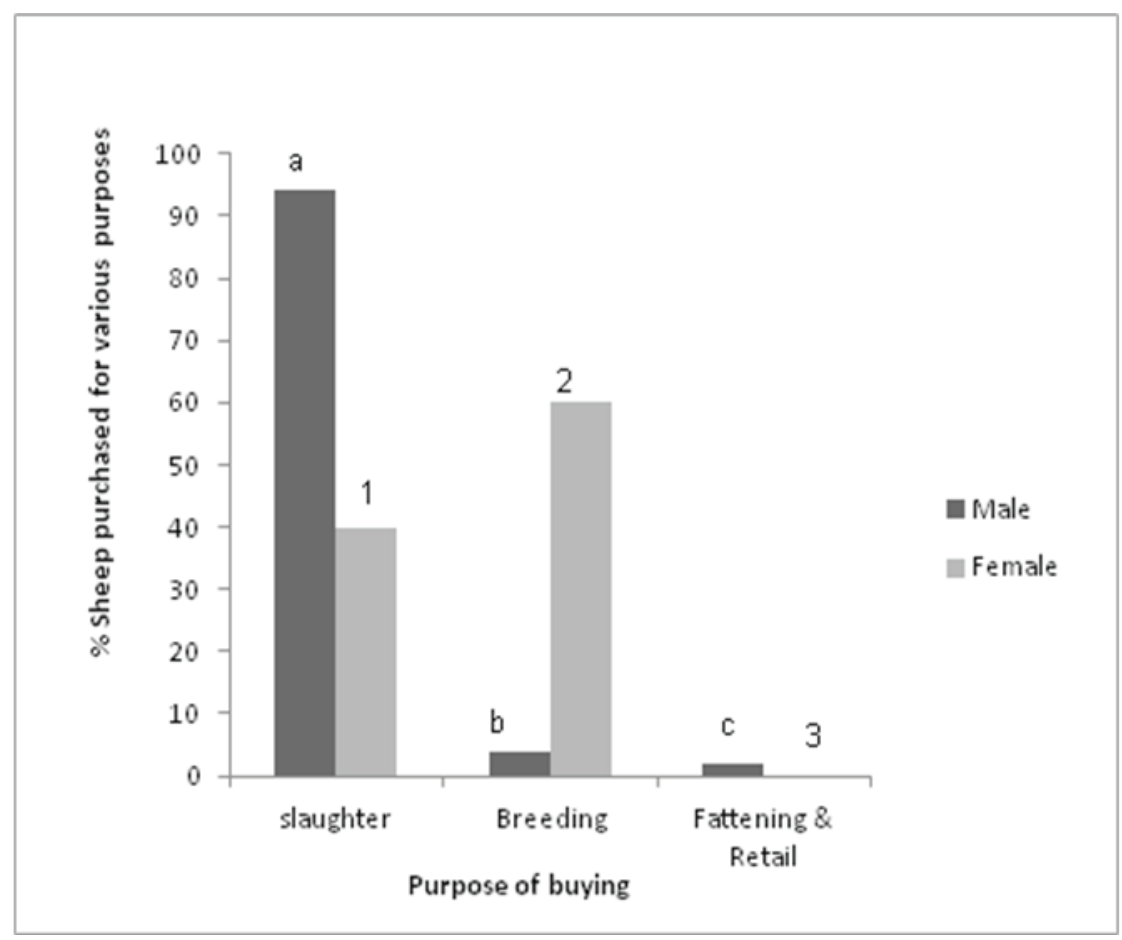

Figure1: Purposes of buying sheep from five markets (Bars with different letters and numbers indicate statistical differences at $\mathrm{P}<0.001$ )

\section{Observations on purchased animals}

Based on their characteristic morphology, majority of sheep brought to the four markets studied were Arsi-Bale breed type. Sheep with brownish color (52\%) were purchased in significantly large number $(\mathrm{P}<0.001)$ than others (Figure 2 ). The pattern of color diversity in the population of sheep in all markets shows higher proportions for brownish and spotted sheep (Data not shown). 


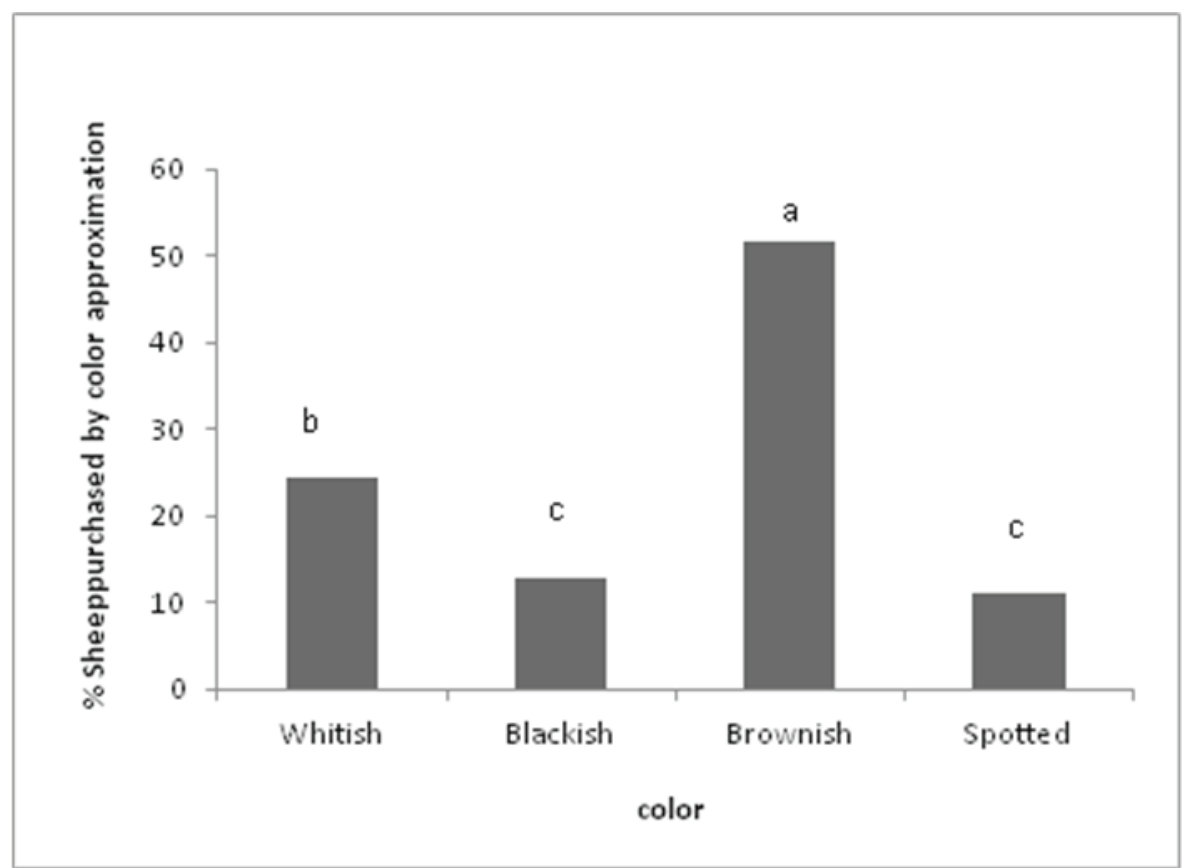

Figure 2. Color distribution of sheep bought from five markets. Bars with different letters are statistically different at $\mathrm{P}<0.001$

\section{Morphometric linear measurement and purpose of buying}

The mean heart girth of sheep bought for retail/trading and slaughter were significantly higher than for those bought for breeding and fattening (Table 2). Sheep purchased for slaughter had larger mean chest size and lumbar width than those bought for other purposes. Similarly, the smallest mean tail width was registered for sheep bought for breeding, which were dominantly females.

Table 2: Comparison of mean price and morphometric parameters in sheep bought for different purposes at the four study markets

\begin{tabular}{lccccc}
\hline Purpose & $\begin{array}{c}\text { Price } \\
\pm \mathrm{SD}(\text { Birr })\end{array}$ & $\begin{array}{c}\text { Heart girth } \\
\pm \mathrm{SD}(\mathrm{cm})\end{array}$ & $\begin{array}{c}\text { Chest size } \\
\pm \mathrm{SD}(\mathrm{cm})\end{array}$ & $\begin{array}{c}\text { Lumbar width } \\
\pm \mathrm{SD}(\mathrm{cm})\end{array}$ & $\begin{array}{c}\text { Tail width } \\
\pm \mathrm{SD}(\mathrm{cm})\end{array}$ \\
\hline Slaughter & $374 \pm 133 \mathrm{a}$ & $73.5 \pm 7.0 \mathrm{a}$ & $13.4 \pm 2.0 \mathrm{a}$ & $15.0 \pm 3.1 \mathrm{a}$ & $13.2 \pm 2.8 \mathrm{a}$ \\
Breeding & $284 \pm 81 \mathrm{~b}$ & $71.5 \pm 5.6 \mathrm{~b}$ & $12.6 \pm 2.0 \mathrm{~b}$ & $14.0 \pm 3.2 \mathrm{~b}$ & $12.2 \pm 2.0 \mathrm{~b}$ \\
Fattening & $262 \pm 45 \mathrm{~b}$ & $70.0 \pm 4.4 \mathrm{c}$ & $12.3 \pm 1.4 \mathrm{~b}$ & $13.1 \pm 2.6 \mathrm{c}$ & $12.7 \pm 3.7 \mathrm{a}$ \\
Trading & $349 \pm 235 \mathrm{a}$ & $76.3 \pm 7.9 \mathrm{~d}$ & $12.5 \pm 1.4 \mathrm{~b}$ & $13.4 \pm 3.0 \mathrm{c}$ & $12.9 \pm 4.1 \mathrm{a}$ \\
\hline
\end{tabular}

SD: standard deviation. Values with different letters are statistically different at $\mathrm{P}<0.01$. 


\section{Purpose of buying and price comparison}

During sheep marketing, call price to selling price ratio in the year 2008 shows that after an intense negotiation, sheep owners accept $84 \pm 7.3 \%$ of the call price. Comparisons of means showed that customers paid significantly higher price $(\mathrm{P}<0.001)$ for males (mean: $374 \pm 118$ Birr) than for females (mean: $292 \pm 62$ Birr). Mean price was significantly higher for sheep purchased for slaughter than for those bought for breeding and fattening $(\mathrm{P}<0.001)$ (Table 2).

\section{Morphometric linear measurement and price correlation}

From linear correlation coefficient determinations depicted in Table 3, it can be observed that price of the animals was significantly and positively correlated with heart girth and the sizes of the three traits most commonly used for selecting animals of choice by sheep market customers (chest size, lumbar width and tail width $(\mathrm{P}<0.01)$. Moreover, heart girth had significant positive relationship with chest size, lumbar width and tail width $(\mathrm{P}<0.01)$.

Table 3. Correlation between price and morphometric parameters of sheep $(n=600)$

\begin{tabular}{lcccc}
\hline Morphometry & \multicolumn{2}{c}{ Heart girth } & \multicolumn{2}{c}{ Price } \\
\cline { 2 - 5 } & r-value & P-value & r-value & P-value \\
\hline Chest size & 0.692 & $\mathrm{P}<0.01$ & 0.787 & $\mathrm{P}<0.01$ \\
Lumbar width & 0.720 & $\mathrm{P}<0.01$ & 0.603 & $\mathrm{P}<0.01$ \\
Tail length & 0.083 & $\mathrm{P}=0.53$ & -0.019 & $\mathrm{P}=0.743$ \\
Tail width & 0.473 & $\mathrm{P}<0.01$ & 0.395 & $\mathrm{P}<0.01$ \\
Heart girth & & & 0.659 & $\mathrm{P}<0.01$ \\
\hline
\end{tabular}

\section{Discussion}

As it was observed in the questioner survey, large number of sheep was bought for slaughter (home consumption and restaurant) than for other purposes. This is partially explained by the fact that most of the animals brought to the markets and marketed were males, which are commonly preferred for slaughter in the Ethiopian tradition. The result of this study agrees with the report of Teressa Adugna (2006) on cattle market in Eastern Ethiopia and Dossa, et al (2008) in southern Benin that indicates that male cattle/sheep dominate in all markets studied and majority were for home consumption and butchering/restaurants. However, Shigdaf Mekiriaw (2012) reported that of the total sheep sold in Farta district, 17.5\% of sheep were bought for consumption purposes while in Lay Gayint district $37.7 \%$ and $23.3 \%$ of sheep were sold 
for resale and consumption purposes, respectively. This variation may be attributed to difference in market access where our study was conducted in an area where access to big markets favours high demand and supply mainly for consumption.

Thys and Hardouin (1991) indicated that weight determination was a major concern for sheep buyers in markets of Cameroon. In this study, it was observed that almost all sheep buyers evaluate chest size (sternal area: "firimba"), lumbar width and tail width as criteria for purchasing sheep. It is true that this traditional practice of palpating such body parts as above is to estimate body weight but to what extent each of them effectively reflects body weight deserves investigation. According to the findings of Agajie Tesfaye (2010), $53 \%$ and $40 \%$ of the overall sample households reported that age and weight, respectively, were the crucial attributes demanded from sheep by customers at the market of Wolemera and Dendi districts of West-central Ethiopia.

In this study, coat color was not an important criterion for sheep buyers in the study areas. However, it was noticed that among the sheep purchased, animals with brownish color dominate over the others. This shows that brownish colored sheep appear more attractive than others. According to a study conducted by Shigdaf Mekuriaw (2012), most buyers have preference for red and white colour (37.18\%) followed by red color (29.74) of sheep and black was the least preferred (2.57\%) in Farta and Washera Weredas of Ethiopia. This is more particularly important for sheep breeders, as this together with other traits of customers' choice could add value and marketability to their animals. In our case, this could also be a matter of supply than market preference since most animals coming to the markets studied were with brownish and spotted colors.

In the absence of weighing scale, a number of body linear measurements such as heart girth values can be used to estimate the weight of an animal (Nsoson et al, 2003; Vargas et al., 2007; Elizabeth Hiale et al., 1997). For example, studies have shown that heart girth can explain $86-91 \%$ of the body weight in sheep (Thys and Harouin, 1991). However, at market levels, the common practice of evaluating selected body parts sometimes depends not only on body weight but also on the purpose for which the animal is purchased. In this study, it is shown that animals purchased for immediate consumption (for home slaughter and restaurant) and resale had higher values of heart girth, chest size and lumbar width than those bought for breeding and fattening suggesting that good body conditioned animals are preferred for immediate use. A similar observation was noted by previous studies where animals with 
good body condition were frequently sold while those with poor condition are kept at home or less preferred at markets (Shigdaf Mekuriaw (2012). The fact that large sized animals are selectively eliminated through slaughter deserves further study as this may have an impact on the future performance of sheep population in the area and elsewhere in the country.

In this study, although direct weight measurement was not done, the strong positive correlation observed between price and heart girth implies the tendency to pay more for larger or heavier animals. Similar findings were reported in goats of Southern Benin (Dossa et al. 2008). Customers' criteria (chest size, lumbar width and tail width) to select animals with good body condition had also shown significant positive relationship with price after negotiation. Similarly, those animals purchased for trading had higher heart girth values and priced higher than the other groups suggesting that they would be resold without additional investment for improvement.

Andargachew and Brokken (1993) have reported that traits of animals, such as age, weight and color were observed to influence prices of livestock at markets. According to Shigdaf Mekuriaw (2012), 90.6\% of interviewed farmers of Farta and Lay Gaint Weredas believe that Washera and crossbred sheep have a higher market value than Farta sheep due to their better growth, larger body size \& conformation, big fat tail and attractive colour.

Although prices depend on supply and demand, which is heavily influenced by the season of the year and the occurrence of religious and cultural festivals or occurrence of drought and weather shocks (Berhanu Gebremedhin et al., 2007; Gezahegn Ayele et al., 2006), this study was undertaken irrespective of these influencing factors. Accordingly, animals for slaughter had better price than those animals bought for breeding, majority of the latter being ewes. Similarly, those animals purchased for trading earned higher price than the other groups. This is in agreement with the fact that sheep bought for slaughter and resale had better conformation and body condition in terms of the linear parameters measured by palpating selected body parts.

In conclusion, customers' criteria (chest size, lumbar width and tail size) are closely associated to the negotiation price of the animals. As heart girth measurements can estimate the live weight of different species of animals, the association between heart girth and values of these linear measures is assumed to show buyer's good understanding of assessing body weight of sheep in relation to the price they are supposed to pay. As there was no fixed price 
in most Ethiopian markets, the mean call price to buying price ratio of $84 \pm 7 \%$ Birr could be used as a fair market for an inexperienced customer. Most sheep, majority being males, were purchased for immediate consumption (home/ restaurant) and animals purchased for slaughter and resale had higher linear measurement values and fetched better price than those bought for other purposes. While the practice of keeping majority of ewes at home should be encouraged, it is also advisable for the farmer to hold large sized rams with colors of best market preference for breeding in order to have offsprings with better body weight and look.

\section{Acknowledgements}

The authors would like to extend special thanks to sheep marketers at Dukem, Bishoftu, Modjo and Adama markets for their willingness to participate in the study and to Dr Ermias Woldemariam for statistical analysis.

\section{References}

Abegaz, S. 2002. Genetic evaluation of production, reproduction and survival in a flock of Ethiopian Horro sheep. PhD thesis. Faculty of Natural and Agricultural Sciences, Department of Animal, Wildlife and Grassland Sciences, University of the Free State, Bloemfontein. 117 pp.

Adugna, T. 2006. Determinants of market prices of cattle in Eastern Ethiopia. Contributed paper prepared for presentation at the International Association of Agricultural Economists Conference, Gold Coast, Australia, August 12-18, 2006. pp15

Andargachew, K. and Brokken, R .F. 1993. Intra-annual sheep price patterns and factors underlying price variations in the central highlands of Ethiopia. Agricultural Economics, 8:125-138.

Ayele, G., Jabbar, M.A., Teklewold, H., Mulugeta, E. and Kebede, G. 2006. Seasonal and inter-market differences in prices of small ruminants in Ethiopia. Journal of Food Products and Marketing, 12: 59-77.

Beyene, K. and Beruk, Y. 1992. Animal genetic resources and breed characterization work in Ethiopia. In: Rege, J.E.O and Lipner,M.E. (eds), African genetic resource; the characterization, conservation and utilization. Proceeding of the research planning workshop held at ILCA (international livestock center for Africa), Addis Ababa Ethiopia, 19-21 February 1992.pp.77-82. 
CSA (Central Statistics Authority). 2004. The 2001/02 Ethiopian Agricultural Sample Enumeration (EASE), Executive Summary, May, 2004, Addis Ababa, Ethiopia

DAGRIS 2006. Domestic Animal Genetic Resources Information System (DAGRIS). (eds. J.E.O. Rege, W. Ayalew, E. Getahun, O. Hanotte and T. Dessie). International Livestock Research Institute, Addis Ababa, Ethiopia. http://dagris.ilri.cgiar.org

Dossa, L.H., Rischkowsky, B., Birner, R. and Wollny C. 2008. Market potential for the local Djallonké goat in Southern Benin: empirical evidence from two rural markets. Livestock research for rural development. http://www.lrrd.org/lrrd20/5/doss20078. htm accessed on 30 Dec. 2011

Ermias, E., Yami, A. and Rege, J.E.O. 2002. Fat deposition in tropical sheep as adaptive attribute to periodic feed fluctuation. Journal of Animal Breeding and Genetics. $119,235-246$.

Gebremedhin, B., Hoekstra, D. and Samson, J. 2007. Heading towards commercialization? The case of live animal marketing in Ethiopia. Improving Productivity and Market Success (IPMS) of Ethiopian Farmers Project Working Paper 5. ILRI (International Livestock Research Institute), Nairobi, Kenya.

Gizaw, S. 2009. Sheep Breeds of Ethiopia: a guide for identification and utilization. In: Yami, A., Awgichew, K., Gipson, TA. and Merkel, RC. (Eds), Technical Bulletin No.28. Ethiopia sheep and goat productivity improvement program (ESGPIP), USAID and MoARD, pp13

Hile, E., Hintz, H.F. and Frb Hn. 1997. Predicting Body weight from body measurements in Asian elephants (Elephas maximus). Department of animal science, Cornell University, Ithaca, New York

Mekuriaw, S., Mekuriaw, Z., Taye, M., Yitayew, A., Assefa, H. and Haile, A . 2012: Traditional management system and farmers' perception on local sheep breeds (Washera and Farta) and their crosses in Amhara Region, Ethiopia. Livestock Research for Rural Development, 24, Article \#4. Retrieved May 11, 2012, from http://www.lrrd.org/lrrd24/1/meku24004.htm

Nsoson, S.J., Aganga, A.A., Monganetsi and Tshwenyane, S.O 2003. Body weight, Body condition score and heart girth in indigenous Tswana goats during the dry and wet seasons in south east Botswana. Livestock Research for Rural Development (15) 4. Retrieved January 4, 2012, from http://www.lrrd.org/lrrd15/4/nsos154.htm 
Tesfaye, A .2010: Demand influencing attributes in the smallholder livestock marketing practices. Livestock Research for Rural Development, 22, Article \#208. Retrieved May 11, 2012, from http://www.lrrd.org//rrd22/11/tesf22208.htm

Thys, E. and Hardouin, J. 1991. Prediction of sheep body weight in markets in the Far North Cameroon. Livestock Research for Rural Development, 3, http://www.lrrd. org/lrrd3/1/hardouin.htm

Tibbo, M. 2006. Productivity and health of indigenous sheep breeds and crossbreds in the central Ethiopian highlands. PhD dissertation. Department of Animal Breeding and Genetics, Faculty for Veterinary Medicine and Animal Sciences, Swedish University of Agricultural Sciences (SLU), Uppsala, Sweden.

Tibbo, M., Ayalew, W., Awugichew, K., Ermias, E. and Rege, J. E. O. 2004. On-station characterization of indigenous Menz and Horro Sheep breeds in the central highlands of Ethiopia. FAO Animal Genetic resources 35: 61-74 DOI: 10.1017/ S1014233900001814

Vargas, S., Labri A., and Sanchez, M. 2007. Analysis of size and conformation of native Creole goat breeds and cross breeds used in small holder agrosilvopastoral systems in Puebla, Mexico. Tropical Animal Health and Production, 39(4): 276-86) 